\title{
SRTM1 ve ASTER Sayısal Yükseklik Modellerinin Gravimetrik Jeoit Belirlemeye Katkısı
}

$\ddot{O} \mathbf{z}$

\author{
H. Tuğba ARLI İL ${ }^{1}$, R. Alpay ABBAK ${ }^{* 2}$, İ. Öztuğ BİLDİi̇Cí2 ${ }^{2}$, Selda DEMİR ${ }^{3}$ \\ ${ }^{1}$ Sağlık Bakanlığı, Sağlık Yatırımları Genel Müdürlüğü, Ankara \\ (arlihtuba@gmail.com) ORCID ID 0000-0002-7186-3685 \\ ${ }^{2}$ Selçuk Üniversitesi, Harita Mühendisliği Bölümü, Konya \\ (aabbak@ selcuk.edu.tr, bildirici@ selcuk.edu.tr) ORCID ID 0000-0002-6944-5329, 0000-0001-7717-586X \\ ${ }^{3}$ Gaziosmanpaşa Üniveristesi, Teknik Bilimler Meslek Yüksek Okulu, Tokat \\ (selda.demir@gop.edu.tr) ORCID ID 0000-0003-3551-3562
}

Gravimetrik jeoit modellerinin oluşturulma sürecinde gravite verilerinin yanı sıra topografik yüksekliklere de ihtiyaç vardır. Çünkü jeoit modelleme çalışmalarında topografya etkisi en önemli parametrelerden biridir ve dünyanın fiziksel yüzeyinden toplanan gravite ölçüleri jeoit modellemede doğrudan kullanılamaz. Serbest hava gravite anomalilerinin enterpolasyonu için herhangi bir Sayısal Yükseklik Modelinden (SYM) alınan grid merkezlerinin ortalama yüksekliklerine gereksinim duyulur. Bu çalışmada SRTM1 ve ASTER SYM'lerin bölgesel gravimetrik jeoit modellemedeki performansları değerlendirilmiştir. Öncelikle çalışma sahasına homojen olarak dağılmış nivelman noktalarıyla modellerin doğrulukları bölgesel anlamda araştırılmıştır. Daha sonra, test bölgesinde SYM'ler sirasıyla kullanılarak KTH (İsveç Kraliyet Enstitüsü) yöntemi ile iki farklı gravimetrik jeoit modeli hesaplanmıştır. Karşılaşılan çeşitli sistematik hataları ortadan kaldırmak ve en uygun kombinasyonu elde etmek için gravimetrik ve GPS-nivelman jeoit modellerini düzeltici yüzeye dayalı olarak optimum yüzeyde birleştirilmiş ve jeoit modellerinin doğrulukları analiz edilmiştir. Sonuç olarak her iki jeoit modeli arasında anlamlı bir fark olmadığı görülmüştür. Modellerin benzer sonuçları vermesi, her iki SYM'nin doğruluklarının yakın olmasından kaynaklandığı değerlendirilmektedir. Ancak SRTM1 Modelinin olmadığ yerlerde ASTER Modelinin alternatif olarak kullanılabileceği önerilmektedir.

AnahtarKelimeler: ASTER, Bölgesel Jeoit Belirleme, SRTM1, KTH Metodu

\section{Contribution of SRTM1 and ASTER Digital Elevation Models to Gravimetric Geoid Determination}

\begin{abstract}
In procedures of gravimetric geoid modeling, the topographic heights are needed as well as gravity data. This is because the terrain effect is one of the most important parameters in gravimetric geoid modeling and gravity surveys collected on physical surface of the Earth are not used directly in geoid modelling. For the interpolation of free-air gravity anomalies, mean heights of grid nodes from any Digital Elevation Model (DEM) are needed. In this study the performances of SRTM1 and ASTER DEMs in regional gravimetric geoid modeling were evaluated individually. Firstly, the accuracies of the models were investigated in regional scale by comparing with leveling data, which are well distributed over test area. Afterwards, the two different gravimetric geoid models were computed with the KTH (Swedish Royal Institute of Technology) method by using the DEMs in sequence. Gravimetric and GPS/leveling geoid models were combined based on a corrector surface to elimination various systematic errors encountered and find optimal combination and the accuracies of the geoid models. As a result, there is no significant difference between the geoid models. It is estimated
\end{abstract}

\footnotetext{
* SorumluYazar
} 
that the models give similar results because the accuracy of both models is close. However, ASTER Model can be used as an alternative in places where the SRTM1 Model is not available.

Keywords: ASTER, SRTM1, KTH Method, Regional Geoid Determination

\section{GİRIŞ}

Fiziksel jeodezinin temel amacı yerin gravite alanı ve bu alanın eşpotansiyel yüzeylerinden biri olan jeoidi belirlemektir. Jeoit, her noktasında çekül doğrultusuna dik, ortalama deniz seviyesiyle çakıştığı varsayılan kapalı bir yüzeydir. Fiziksel yeryüzünde meydana gelen değişimlerin özellikle mühendislik uygulamalarında büyük önem taşıyan suyun hareketinin izlenebilmesi ve yükseklik sistemlerinde kullanılacak ideal bir referans yüzeyin oluşturulması, jeoidin tanımlanması ile mümkündür.

Kullanılan verilere göre jeoit modeli 3 farklı yöntemle belirlenir. Bunlar elipsoit ve astronomik koordinatlar arasındaki çekül sapmalarını kullanan astro-jeodezik yöntem, elipsoidal-ortometrik yükseklik farklarını esas alan GPS-nivelman yöntemi ve yersel gravite gözlemleri, Sayısal Yükseklik Modeli ve Global Yerpotansiyel Modelden oluşan bir sentezi kullanan gravimetrik yöntemdir. Gravimetrik yöntem Stokes fonksiyonu yardımıyla ağırlıklandırılmış yüzey gravite verilerinin integrasyonu ile bir noktadaki jeoit yüksekliği değerinin elde edilmesini sağlar (Abbak, 2017).

Yersel ve uzaysal gravite verileri birlikte değerlendirilerek yeryuvarının gerçek şeklini temsil eden bir gravimetrik jeoit modeli oluşturulabilir. Jeoit yüksekliği, çekül sapması ve gravite anomalileri gibi büyüklükler yeryuvarının çekim alanını temsil eden bir Global Yerpotansiyel Model (GGM: Global Geopotential Model) ile hesaplanabilir. Uygulamada bu büyüklükler GGM yardımıyla sınırlı bir doğrulukta elde edilebildiğinden Stokes fonksiyonunun modifikasyonu sayesinde GGM'lerden elde edilen uzun dalga boylu bileşenler ile yersel verilerden elde edilen kısa dalga boylu bileşenler belirli katsayılarla birleştirilerek değerlendirildiğinde yüksek doğruluklu ve çözünürlüklü bir jeoit modeli oluşturulabilir. Gravimetrik jeoit modellerinin oluşturulma sürecinde gravite verilerinin yanı sıra topografik yüksekliklere de ihtiyaç vardır. Fiziksel yeryüzünden toplanan gravite ölçümleri jeoit modellemede doğrudan kullanılamaz. Gravite ölçüleri, ortalama deniz seviyesine ve enterpole edilmiş grid merkezlerine indirgenmelidirler. Daha sonra serbest hava gravite anomalileri, hesaplama noktasında bir jeoit yüksekliği üreten Stokes fonksiyonunda değerlendirilir. Serbest hava gravite anomalilerinin enterpolasyonu için herhangi bir Sayısal Yükseklik Modelinden (SYM) alınan grid merkezlerinin ortalama yüksekliklerine ihtiyaç vardır. GTOPO30 (Global TOPOgraphy), ACE (Altimetry Corrected Elevations), SRTM (Shuttle Radar Topography Mission) ve ASTER (Advanced Spaceborne Thermal Emission and Reflection Radiometer) başlıca kullanılan Global sayısal yükseklik modelleridir. Genellikle SYM'lerin çözünürlükleri 1", 3" ve 30" grid aralığında değişmektedir.

Gravimetrik jeoit belirlemeye katkıda bulunan SYM'ler ile ilgili yapılan çalışmalardan 3 tanesi örnek olarak verilebilir. Bunlardan ilki, Merry (1999); Molodensky yaklaşımını kullanarak Afrika'daki yükseklik anomalisini hesaplamada bazı Global ve bölgesel Sayısal Yükseklik Modellerini karşılaştırmaktadır. Ayrıca Kiamehr ve Sjöberg (2005) bazı bölgesel ve Global Sayısal Yükseklik Modellerini hesaba katarak SRTM3 (3 saniye çözünürlüklü) SYM'nin jeoit belirlemeye katkısını incelemektedir. Son olarak Abbak (2014), bir engebeli test bölgesi Auvergne'de (Fransa) ortalama gravite anomalilerinin kestirimi için ASTER ve SRTM3 SYM'lerin karşılaştırılması üzerine bir çalışma yapmıştır. Şimdiki çalışmanın diğer örneklerden farkı; orta engebeli bir test alanında, 1 saniye çözünürlüklü SYM'leri karşılaştırılarak uygulanmasidır.

Bu çalışmada, sayısal yükseklik modellerinin bölgesel gravimetrik jeoit modellemedeki performansları değerlendirilmiştir. $\mathrm{Bu}$ amaçla Konya Kapalı Havzası test bölgesi (yaklaşık $70000 \mathrm{~km}^{2}$ ) olarak seçilmiş̧tir. Global Sayısal Yükseklik Modellerinden, en güncel ve 
Global doğruluğu ve çözünürlüğü yüksek (1 sn çözünürlüklü) olan iki tanesi (SRTM1 ve ASTER) test verisi olarak seçilmiştir. Çalışma sahası içinde homojen olarak dağılmış nivelman noktalarıyla modellerin doğrulukları bölgesel anlamda araștırılmıştır. Daha sonra, test bölgesinde SRTM1 ve ASTER Sayisal Yükseklik Modelleri sırasılla kullanılarak, iki farklı gravimetrik jeoit modeli hesaplanmıştır. Gravimetrik jeoit modelleme işlemlerine, sınırlı sayıda gravite verisi bulunduran dağlık alanlarda başarılı sonuçlar veren KTH (Kungliga Tekniska Högskolan) yöntemi kullanılmıştır (Abbak, 2011). Her yükseklik modelinin jeoit modelleme çalışmalarındaki performansı ayrı ayrı değerlendirilmiş, jeoit modellerinin mutlak doğrulukları GPSnivelman verileri yardımıyla analiz edilmiştir.

Sonuç olarak test bölgesinde en başarılı Sayısal Yükseklik Modeli belirlenerek, söz konusu Sayısal Yükseklik Modelinin doğruluğunun, gravimetrik jeoit modelinin doğruluğuna ne kadar bir katkısı olduğu irdelenmiştir.

\section{YÖNTEM}

$\mathrm{Bu}$ bölümde sayısal uygulamada kullanılacak KTH tekniği ve düzeltici yüzeyler (corrector surfaces) hakkında teorik bilgiler verilecektir.

\subsection{KTH Tekniği}

1849 yılında İrlandalı bilim adamı George Gabriel Stokes gravimetrik olarak Global jeoidin hesaplanmasını sağlayan Stokes integralini yayımlamıştır.

Stokes integrali yeryuvarına homojen olarak dağılmış gravite anomalilerinden jeoit yüksekliğinin belirlenebileceğini ifade eder. Stokes formülünün kullanılması, jeoit üzerindeki her nokta için verilen gravite anomalilerinden bir potansiyelin hesaplanmasıyla ilgilidir (Sideris, 1994). Pratikte istenilen yüksek doğruluklu gravite verilerinin sinırlı bir bölgede elde edilmesi çalışma alanını kısıtlamış olacağından bu integralin belirli bir alan için kesilmesini gerekli kılar. Daha sonrasında kesme hatası ile birlikte veri hatalarını da göz önünde bulundurulması gerektiğini ifade eden İsveç Kraliyet Teknoloji Enstitüsü'nden (KTH)
Prof. Lars Erik Sjöberg bu tekniklere alternatif olacak KTH yaklaşımını önermiştir. KTH yöntemi Stokes fonksiyonunun en küçük kareler yöntemi ile modifikasyonu (LSMS: The Least Squares Modification of Stokes Function) olarak da adlandirılır.

LSMS'de düzeltilmiş jeoit ondülasyonu $\widehat{N}$ aşağıdaki formül yardımıyla belirlenebilir.

$\widehat{\mathrm{N}}=\widetilde{\mathrm{N}}+\delta \mathrm{N}_{\text {comb }}^{\mathrm{Top}}+\delta \mathrm{N}_{\mathrm{comb}}^{\mathrm{Atm}}+\delta \mathrm{N}^{\mathrm{DWC}}+\delta \mathrm{N}^{\mathrm{Ell}}$

Eşitlikte geçen $\widetilde{\mathrm{N}}$ yaklaşık jeoit ondülasyonu yersel gravite verisi ve GGM'den hesaplanır. $\delta \mathrm{N}_{\text {comb }}^{\text {Top }}$ kombine topografik düzeltmeyi, $\delta \mathrm{N}_{\text {comb }}^{\text {Atm }}$ kombine atmosferik düzeltmeyi, $\delta \mathrm{N}^{\mathrm{DWC}}$ indirgeme düzeltmesini (downward continuation), $\delta \mathrm{N}^{\text {Ell }}$ ise elipsoidal düzeltmeyi temsil etmektedir.

En küçük kareler yöntemi ile Stokes fonksiyonun modifikasyonu, yersel gravite verisi ile gravite alanının uzun dalga boylu bileşenlerini belirli katsayılarla birleştirerek kesme hatasını en aza indirgemeye çalışan stokastik bir yöntemdir. Stokes fonksiyonu LSMS ile yeniden düzenlenerek aşağıdaki eşitliğe dönüşür.

$\widetilde{\mathrm{N}}=\frac{\mathrm{R}}{4 \pi \gamma} \iint_{\sigma_{0}} \mathrm{~S}^{\mathrm{L}}(\psi) \Delta \mathrm{gd} \sigma+\frac{\mathrm{R}}{2 \gamma} \sum_{\mathrm{n}=2}^{\mathrm{L}} \mathrm{b}_{\mathrm{n}} \Delta \mathrm{g}_{\mathrm{n}}^{\mathrm{GGM}}$

Burada R yeryuvarının ortalama yarıçapını, $\gamma$ elipsoit üzerinde normal graviteyi, $\sigma_{0}$ çalışma bölgesini, d $\sigma$ çalışma bölgesinin en küçük yüzey elamanını, $\Delta \mathrm{g}$ gravite anomalisini, $\mathrm{b}_{\mathrm{n}}$ KTH modifikasyon parametresini, $\Delta \mathrm{g}_{\mathrm{n}}^{\mathrm{GGM}}$ GGM'den türetilen $n$. derecedeki gravite anomalisi, $S^{\mathrm{L}}(\psi)$ yerel Stokes fonksiyonunu, $\psi$ yermerkezli açıyı, $L$ yerpotansiyel modelin kullanılan en büyük açınım derecesini $\left(L \leq N_{\max }\right) \quad$ ve aynı zamanda Stokes fonksiyonunun yerel bileşenini temsil eder.

Topografik düzeltme,

$\delta \mathrm{N}_{\text {comb }}^{\text {Top }}=-\frac{2 \pi \mathrm{G} \rho}{\gamma} \sum_{\mathrm{n}=2}^{\infty} \mathrm{H}_{\mathrm{n}}^{2}$

eşitliğiyle ifade edilir (Sjöberg, 2007). Burada $\rho$ yer kabuğunun yoğunluğunu, $G$ evrensel çekim sabitini, $H$ grid merkezinin ortalama yüksekliğini temsil etmektedir. Stokes integrasyonu fiziksel yeryüzü ve jeoit arasında topografik kitlelerin bulunmadı $\breve{g}_{1}$ varsayımına dayanır. Bu nedenle oluşan hatayı gidermek 
için yeryuvarının dışındaki topografya ortalama bir yoğunluğa göre sonradan hesaba katılır. Topografik düzeltme direkt ve dolaylı etkilerden meydana geldiği için birleşik topografik düzeltme olarak adlandırılır.

Atmosferik düzeltme terimi,

$\delta \mathrm{N}_{\mathrm{comb}}^{\mathrm{Atm}}=-\frac{\mathrm{GR} \rho^{\mathrm{a}}}{\gamma} \iint_{\rho^{\mathrm{a}}} \mathrm{S}^{\mathrm{L}}(\psi) \mathrm{H}_{\mathrm{p}} \mathrm{d} \sigma$

şeklinde hesaplanabilir (Sjöberg, 1999). Burada $\rho^{\mathrm{a}}$ deniz seviyesindeki atmosfer yoğunluğunu, $H_{p}$ hesap noktasının topografik yüksekliğini gösterir ki bu değer de yine SYM'den türetilen ortalama yüksekliktir. Stokes integrali yeryuvarın dışında atmosferin olmadığını kabul gördüğünden bu eşitlik atmosferik kitlelerin etkisini ortalama bir yoğunluğa göre hesaba katar.

Elipsoidal düzeltme;

$\delta \mathrm{N}^{\mathrm{Ell}}=\left[\left(0.0036-0.0109 \sin ^{2} \varphi\right) \Delta \mathrm{g}+0.0050 \widetilde{\mathrm{N}} \cos ^{2} \varphi\right] \mathrm{Q}_{0}^{\mathrm{L}}$

eşitliği ile hesaplanır (Ellmann ve Sjöberg, 2004). Eşitlikte geçen $Q_{0}^{\mathrm{L}}$ Molodensky kesme katsayısını, $\widetilde{\mathrm{N}}$ yaklaşık jeoit ondülasyonunu ve $\varphi$ hesap noktasının cografi enlemini ifade eder. Stokes integrali gravite anomalisinin küre yüzeyinde hesaplandığını kabul ettiğinden, bu eşitlik jeoit yüksekliklerini elipsoit yüzeyine indirgeyerek düzeltme getirir.

İndirgeme düzeltmesi aşağıdaki üç bileşenden oluşur:

$\delta \mathrm{N}^{\mathrm{DWC}}=\delta \mathrm{N}_{\mathrm{dwc}}^{(1)}+\delta \mathrm{N}_{\mathrm{dwc}}^{\mathrm{L} 1, \mathrm{Far}}+\delta \mathrm{N}_{\mathrm{dwc}}^{\mathrm{L} 2}$

$\mathrm{Bu}$ bileşenler,

$\delta \mathrm{N}_{\mathrm{dwc}}^{(1)}=\frac{\Delta \mathrm{g}}{\gamma} \mathrm{H}_{\mathrm{P}}+3 \frac{\widetilde{\mathrm{N}}}{\mathrm{r}_{\mathrm{P}}} \mathrm{H}_{\mathrm{P}}-\left.\frac{1}{2 \gamma} \frac{\partial \Delta \mathrm{g}}{\partial \mathrm{r}}\right|_{\mathrm{P}} \mathrm{H}_{\mathrm{P}}^{2}$

$\delta N_{d w c}^{\mathrm{L1}, \mathrm{Far}}=\frac{\mathrm{R}}{2 \gamma} \sum_{\mathrm{n}=2}^{\mathrm{M}} \mathrm{b}_{\mathrm{n}}\left[\left(\frac{\mathrm{R}}{\mathrm{r}_{\mathrm{P}}}\right)^{\mathrm{n}+2}-1\right] \Delta \mathrm{g}_{\mathrm{n}}$

$\delta \mathrm{N}_{\mathrm{dwc}}^{\mathrm{L} 2}=\frac{\mathrm{R}}{4 \gamma \pi} \iint_{\sigma_{0}} \mathrm{~S}^{\mathrm{L}}(\psi)\left(\left.\frac{\partial \Delta \mathrm{g}}{\partial \mathrm{r}}\right|_{\mathrm{P}}\left(\mathrm{H}_{\mathrm{P}}-\mathrm{H}_{\mathrm{Q}}\right)\right) \mathrm{d} \sigma_{\mathrm{Q}}$

şeklinde siralanabilir (Sjöberg, 2003). Burada $r_{P} \quad P$ noktasının küresel yarıçapını $\left(r_{P}=\mathrm{R}+\mathrm{H}_{\mathrm{P}}\right), \quad \mathrm{H}_{\mathrm{P}}$ hesap noktasinın ortometrik yüksekliğini, $\mathrm{H}_{\mathrm{Q}}$ integrasyon noktasının orotometrik yüksekliğini, $b_{n}$ modifikasyon parametresini temsil eder. Jeoit modelleme işleminde yersel gravite ölçüleri deniz seviyesine indirgenerek kullanılmaktadır. İndirgeme etkisi jeoit yüksekliğine göre değişen bir yaklaşım olduğundan Stokes integrali gravite anomalisinin yüksekliğe göre doğrusal olarak değiştiği varsayımına sebep olur. $\mathrm{Bu}$ varsayımda hata olacağından indirgeme düzeltmesi yapılır.

Yukarıdaki eşitliklerden anlaşılacağı üzere, topografik, atmosferik ve indirgeme düzeltmeleri grid merkezlerinin ortalama yüksekliğiyle doğrudan ilişkilidir.

\subsection{Düzeltici Yüzeyler}

Jeodezik literatürde iki farklı yükseklik bilgisi; datum kayıklığı, uzun dalga boylu bileșenler gibi sistematik hatalar nedeniyle doğrudan karşılaştırılmamaktadır. Farklı yükseklik verisi türleri arasındaki sistematik hataları gidermek için bir düzeltici yüzeyden yararlanılır. Bu yönteme göre her iki yüzey (gravimetrik jeoit ile GPS-nivelman jeoidi) arasında düzeltici bir yüzey belirlenir. Böyle bir karşılaştırma geleneksel olarak aşağıdaki eşitliğe dayanmaktadır.

$\Delta N=N_{\text {Gravimetrik }}-N_{\text {Geometrik }}=\mathbf{a}^{\mathrm{T}} \mathbf{x}+\varepsilon$

Burada a katsayılar matrisi, $\mathbf{x}$ bilinmeyen parametreler vektörü, $\varepsilon$ rastgele hata terimidir. $\mathrm{Bu}$ parametrik modelin gravimetrik ve GPSnivelman jeoitleri arasındaki sistematik hataları doğal olarak ortadan kaldırıldığ varsayılır. $\mathrm{Bu}$ tür karşılaştırmalarda yaygın olarak dört, beş ve yedi parametreli benzerlik dönüşümleri önerilmektedir. $\mathrm{Bu}$ çalışmada kullanılan 7 parametreli benzerlik dönüşümü aşağıdaki gibi tanımlanmıştır.

$\boldsymbol{a}=\left[\begin{array}{c}\cos \varphi_{\mathrm{i}} \cos \lambda_{\mathrm{i}} \\ \cos \varphi_{\mathrm{i}} \sin \lambda_{\mathrm{i}} \\ \sin \varphi_{\mathrm{i}} \\ \cos \varphi_{\mathrm{i}} \sin \varphi_{\mathrm{i}} \cos \lambda_{\mathrm{i}} / \mathrm{W}_{\mathrm{i}} \\ \cos \varphi_{\mathrm{i}} \sin \varphi_{\mathrm{i}} \sin \lambda_{\mathrm{i}} / \mathrm{W}_{\mathrm{i}} \\ \sin ^{2} \varphi_{\mathrm{i}} / \mathrm{W}_{\mathrm{i}} \\ 1\end{array}\right]$

$\varphi_{i}$ ve $\lambda_{i}$, i'nci kontrol noktasının coğrafi (jeodezik) koordinatlarıdır. $W_{i}$ katsayısı, 


$$
W_{i}=\sqrt{1-e^{2} \sin ^{2} \varphi_{i}}
$$

eşitliğiyle ifade edilmektedir. Burada e referans elipsoidinin birinci dışmerkezliğini göstermektedir.

GPS noktalarında hesaplanan a katsayılar vektörü bir araya getirilerek A katsayllar matrisine dönüştürülür. Daha sonra 7 parametreli benzerlik dönüşüm modeli En Küçük Kareler yaklaşımıyla;

$$
\mathbf{x}=\left(\mathbf{A}^{\mathrm{T}} \mathbf{A}\right)^{-1} \mathbf{A}^{\mathrm{T}} \mathbf{l}
$$

bilinmeyenler hesaplanır. Buradaki I ölçü vektörü gravimetrik ve geometrik jeoit yükseklikleri arasındaki fark matrisidir. Ölçülere eklenecek düzeltme değerleri vektörü;

$\mathbf{v}=\mathbf{A x}-\mathbf{l}$

ve bu değerlerden hesaplanan birim ağırlıklı ölçünün standart sapmas1;

$\mathrm{m}_{0}=\sqrt{\frac{\mathbf{v}^{\mathrm{T}} \mathbf{v}}{\mathrm{n}-\mathrm{u}}}$

eşitlikleriyle gösterilmektedir. Eşitlikteki $n$ GPS-nivelman nokta sayisıni, $u$ ise bilinmeyen sayısını ifade etmektedir. Parametrik model $\varepsilon$ karelerinin toplamını en aza indiren En Küçük Kareler yöntemi ile çözülmüştür. Son değerlendirme modelin kesin hatası değildir, çünkü karesel ortalama hata; nivelman, GPS ve enterpolasyondan kaynaklanan hataları da içermektedir.

\subsection{Veri Toplama}

$\mathrm{Bu}$ bölümde sayısal uygulamada kullanılacak veriler hakkında bilgiler verilecektir.

\subsection{1. Çalıșma sahası}

Konya, Karaman, Aksaray ve Niğde illeri dahil olmak üzere Konya Kapalı Havzasını kaplayan bölge uygulama sahası seçilmiştir. Çalışma sahası $37^{\circ} \leq \varphi \leq 39^{\circ}$ kuzey paralelleri, $31.5^{\circ} \leq \lambda \leq 35.0^{\circ}$ doğu meridyenleri arasında kalan yaklaşık $70000 \mathrm{~km}^{2}$ yüzölçümlü bir alanı kaplamaktadır (Şekil 1).

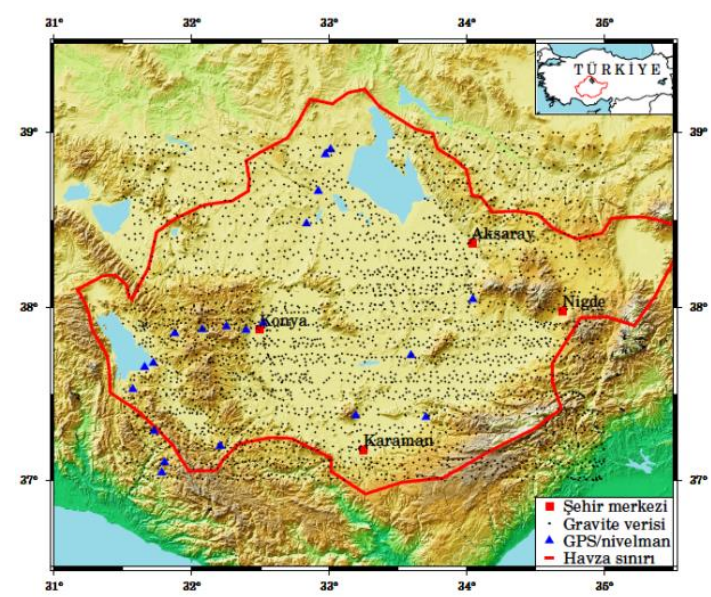

Şekil 1. Proje sahasının topografik durumu ve verilerin dağglımı (Abbak, 2011)

Bölgenin ortalama yüksekliği $1250 \mathrm{~m}$ iken, söz konusu yükseklikler Göksu vadisinde 700 metreden, Toros Dağları'nda yaklaşık 3500 metreye kadar çıkmaktadır.

\subsubsection{Kontrol verileri}

$\mathrm{Bu}$ çalışmada kullanılacak kontrol verileri, Türkiye Ulusal Düssey Kontrol Ağı 1999 (TUDKA99) birinci derece nivelman ağından temin edilen ve ortometrik yükseklikleri bilinen toplam 24 adet GPS-nivelman noktalarıdır. Düşey datum Antalya Maraegrof istasyonuna göre belirlenmiştir. Çalışma sahasında bulunan elipsoidal yüksekliklerin ve ortometrik yüksekliklerin doğruluğu (Antalya mareograf istasyonuna olan uzaklığına bağlı olarak) $1-3 \mathrm{~cm}$ arasında değişmektedir.

\subsubsection{Gravite verileri}

Yersel gravite gözlemleri ile bozucu gravite alanına ilişkin temel büyüklük olan gravite anomalileri hesaplanır. Bu çalışmada Türkiye yersel gravite veri kütüğünden sorumlu Harita Genel Komutanlığından, Abbak (2011) tarafından gerçekleştirilen proje kapsamında satın alınan 3073 adet gravite gözlemleri kullanılmaktadır. Şekil 1'de çalışma sahasındaki gravite gözlemlerine ilişkin noktaların coğrafi dağılımı gösterilmiștir. Her nokta için gravite bilgisi sirasıyla, gravite noktasinın enlemi, boylami, ortometrik yüksekliği (Antalya mareograf istasyonundaki ortalama deniz seviyyesinden) ve gravite değeridir. Coğrafi koordinatlar World 
Geodetic System 1984 (WGS84), gravite değerleri ise International Gravity Standardization Net 1971 (IGSN71) datumundadır.

\subsubsection{Sayısal yükseklik modelleri}

Sayısal Yükseklik Modelleri seçilirken modelin güncelliğii, doğruluğu ve çözünürlüğü dikkate alınmıştır. $\mathrm{Bu}$ nedenle Global doğruluğu yüksek ve çözünürlüğü 1 saniye aralıklı en güncel Global Sayısal Yükseklik Modellerden olan SRTM1 ve ASTER Modelleri test verisi olarak seçilmiştir. Sayısal Yükseklik Modelleri internette kullanıcılara ücretsiz sunulmaktadır. Global düşey doğruluğu 7-14 $\mathrm{m}$ aralığında bulunan ASTER Modeli ile Global düşey doğruluğu \pm 16 m olan SRTM1 Modeli web adreslerinden indirilmiştir (ASTER, 2018; SRTM, 2018). Her iki modelde yatay datum olarak WGS84 ve düşey datum olarak EGM96 (Earth Gravitational Model 1996) jeodini referans alır.

\subsubsection{Seçilen global yerpotansiyel model}

GGM'ler yeryuvarının gravite potansiyelini küresel harmonik seriler yardımıyla temsil eder. Üretilen her model kendinden önceki modelden daha fazla ölçü ve yeni ölçme teknolojisi içerdiğinden son yayınlananlar çalışmalarda tercih edilmektedir. Uluslararası Yer Modelleri Merkezi (ICGEM: International Centre for Global Earth Models) resmi sitesinde bu modeller yayınlanmaktadır (ICGEM, 2018). Her modelin standart sapmaları ve küresel harmonik katsayıları internetten ücretsiz olarak indirilebilir. $\mathrm{Bu}$ çalışmada; daha önce aynı proje sahasında GGM'lerle yapılan bölgesel analize göre en yüksek doğruluklu sonuç veren ITU_GGC16 (Akyilmaz ve ark. 2016) Modeli kullanılmıştır (Demir ve Abbak, 2017). ITU_GGC16, Türkiye Bilimsel ve Teknolojik Araştırma Kurumu'ndan (TÜBİTAK) 113Y155 no'lu araştırma desteği ile uluslararası işbirlikçi olarak İTÜ ve OSU tarafından çeșitli ulusal kurumların işbirliğiyle, ITU_GRACE16 (d/o 180'e kadar) ve GO_CONS_GCF_2_TIM_R5 (d/o 280'e kadar) kombinasyonundan 280 dereceye kadar hesaplanan statik bir global yer potansiyel modeldir (ITU_GGC16, 2018).

\section{UYGULAMA}

$\mathrm{Bu}$ uygulamada öncelikle bölgesel ölçekte Sayısal Yükseklik Modellerinin dış doğruluk analizleri gerçekleştirilecektir. $\mathrm{Bu}$ sonuçlardan yola çıkarak, belirtilen Sayısal Yükseklik Modellerinin bölgesel doğrulukları ortaya konacaktır. Bu kapsamda ele alınan Sayısal Yükseklik Modelleri Konya Kapalı Havzası ölçeğinde bölgesel gravimetrik jeoit modellerin hesaplanmasında yardımc girdi parametresi olarak kullanılacaktır. Her bir bölgesel gravimetrik jeoit modelinin doğruluğu GPS-nivelman verileriyle mutlak anlamda değerlendirilecektir. Sonuçta SYM'lerin doğruluğunun hesaplanan bölgesel gravimetrik jeoit modelinin doğruluğuna yaptığı katkılar sayısal anlamda ortaya konulacaktır.

\subsection{SYM'lerin Karşılaştırılması}

Global SYM'lerin bölgesel doğruluklarının değerlendirilmesi amacıyla çalışma sahası içindeki 3073 noktaya ait ASTER ve SRTM1 Modellerinin topografik yükseklik değerleri Thin Plate Spline enterpolasyonu ile elde edilmiştir. $\mathrm{Bu}$ işlem üçüncü yazar tarafindan $\mathrm{C}$ dilinde geliştirilen bir yazılım ile yapılmıştır. Her model için hesaplanan yükseklikler GPS-nivelman yükseklikleri ile karşılaştırılmıştır. Karşılaştırma sonucunda, uyuşumsuz ölçüler (güven aralığına göre jeodezik çalışmalarda genellikle modelin standart sapmasinın 3 katı hata sınırı olarak kabul edildiğinden) 3-sigma kuralı ile elenmiştir. Elemeler sonucunda geriye kalan 2992 nokta ile SRTM1 Modeli için ve 2993 nokta ile ASTER Modeli için değerlendirmeler yapılmıştır. Diğer yandan karşılaştırma işleminde $\left(\mathrm{H}_{\text {nivelman }}-\mathrm{H}_{\mathrm{SYM}}\right)$, sayısal değerler doğrudan karşılaştırılmayıp, yükseklik sistemleri arasındaki datum tutarsızlıkları ve uzun dalga boylu bileşenler vb. hataların olabileceği göz önünde bulundurularak 7 parametreli benzerlik dönüşümü (düzeltici yüzey) uygulanmıştır. Dönüşüm sonucunda her bir model için yükseklik farkları arasındaki minimum, maksimum, ortalama ve karesel ortalama hata 
değerleri (KOH) hesaplanarak SYM'lerin bölgesel doğrulukları ortaya konmuştur (Tablo 1).

Tablo 1. Nivelman verileriyle SYM'lerin doğruluk testi $[\mathrm{m}]$

\begin{tabular}{llllll}
\hline $\begin{array}{l}\text { Yükseklik } \\
\text { Modeli }\end{array}$ & $\begin{array}{l}\text { Nokta } \\
\text { Sayıs }\end{array}$ & Min. & Max. & Ort. & KOH \\
\hline SRTM1 & 3073 & -50.46 & 47.43 & 0.00 & 11.64 \\
ASTER & 3073 & -52.77 & 50.47 & 0.01 & 12.80 \\
\hline
\end{tabular}

$\mathrm{Bu}$ istatiksel sonuçlara göre SRTM1 Modelinin, ASTER Modeline göre 1.10 kat daha yüksek doğruluklu olduğu görülmektedir. Teorik olarak ASTER'in SRTM1'in doğruluğundan yüksek olmasına karşın bölgesel anlamda tam tersi bir sonuç çıkmasının, çalışma sahasının topografyası ile ilgili olduğu düşünülmektedir. Bunun yanı sıra ASTER Modelinin dağlık bir topografyada daha iyi sonuç verdiği her iki modelin Türkiye genelinde değerlendirildiği bir makalede (Bildirici ve Abbak, 2017) bildirilmekte olup, ayn makalede genel istatistikler göz önüne alındığında yine SRTM1 Modelinin ASTER Modeline göre daha yüksek doğruluklu sonuçlar verdiği belirtilmektedir. Çalışma sahasının topografyas1 düşünüldüğünde \%60'ının düzlüklerden oluşması, dağlık alanlarda ASTER Modeline göre iyi sonuçlar elde edemeyen SRTM1 Modeli için bir avantaj olduğu değerlendirilmektedir. Ayrıca ASTER SYM'nin, SRTM SYM'nin görüş kapsamına girmeyen $\left(60^{\circ}\right.$ kuzey ve $56^{\circ}$ güney enlemleri dışında kalan bölgeler) dik dağlık bölgeleri de $\left(83^{\circ}\right.$ kuzey ve güney enlemleri arasındaki bölge) kapsadığı unutulmamalıdır. Diğer yandan SYM'ler arasındaki yükseklik farkları Şekil 2'de gösterilmektedir.

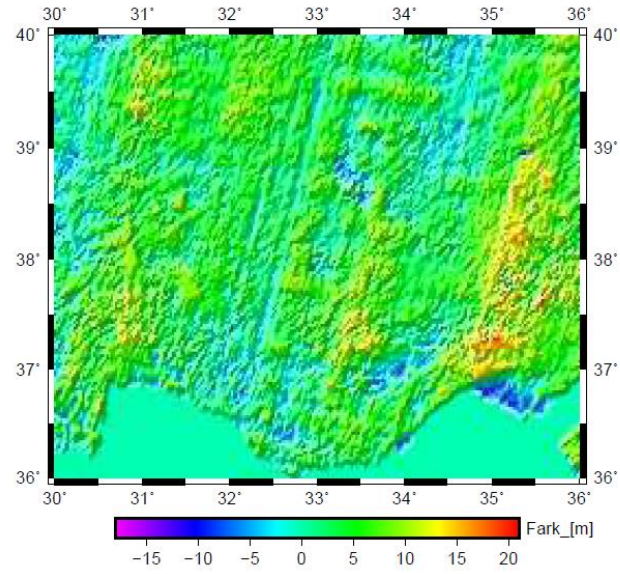

Şekil 2. SYM'ler arasındaki yükseklik farkları [m]

Şekil 2'de SYM'ler arasındaki yükseklik farkları $\% 90$ olasılıkla \pm 10 metre arasında değişmektedir. $\mathrm{Bu}$ fark dağlık kesimlerde 20 metreye kadar çıkmaktadır.

\subsection{Gravite Anomalileri}

Jeoit belirleme amacı doğrultusunda gravitesi ölçülen noktanın yüksekliği yerin gravite alanı belirlenirken göz önünde bulundurulmalıdır. $\mathrm{Bu}$ amaçla jeoit belirlerken jeoit seviyesine indirgenmiş anomaliler kullanılmalıdır. İndirgeme işlemi, gravite verilerindeki topografik bileşenlerin matematiksel olarak ortadan kaldırılmasıdır. Jeoit modellemede, boşlukta gravite anomalisi kullanılmasına karşın, Bouguer anomalileri gridleme işlemindeki enterpolasyon sürecinde temel veridir.

Boşlukta gravite anomalisi fiziksel yeryüzünde ölçülen gravite değeri ile elipsoit üzerindeki normal gravite değerinin arasındaki farktır. Buna göre boşlukta gravite anomalisi;

$\Delta g_{F A}=g_{P}-\gamma_{Q}$

eşitliğiyle hesaplanır. Ancak boşlukta gravite anomalisi ile düşünsel olarak jeoit yüzeyine sıkıştırılan kitleler gerçekte topografya ile yüksek korelasyonludur. Bu durum gridlenme aşamasında karşımıza büyük bir problem olarak ortaya çıkmaktadır. Yerel kitlelerden kaynaklanan bağımlıı̆̆ gidermek için topografik etki basit bir yaklaşımla sabit yoğunluklu kabul edilerek basit Bouguer 
gravite anomalilerine dönüştürülür. Basit Bouguer indirgemesi;

$\Delta g_{S B}=\Delta g_{F A}-2 \pi G \rho H$

eşitliğiyle gösterilir. Burada $\rho$ Bouguer plakasının yoğunluğunu, $H$ ise yersel gravite gözleminin yapıldığı yerin ortometrik yüksekliğini temsil eder. Dağınık halde bulunan Bouguer anomalileri Bjerhammar kuralına (Bjerhammar, 1973) uygun olarak en yakın komşuluk enterpolasyon ile grid merkezlerine taşınmıştır. Gridleme işlemi yapıldıktan sonra jeoit modellemede kullanılacak olan boşlukta gravite anomalilerine geçiş yapmak için Bouguer anomalilerine, gridlerin Bouguer plakası etkisi geri eklenmelidir.

$\Delta g_{F A}=\Delta g_{S B}+2 \pi G \rho H$

SYM'lerden üretilen yüksekliklerin ortalamaları alınarak grid merkezlerinde $0.02^{\circ} \times 0.02^{\circ}$ çözünürlüğünde ortalama grid yükseklikleri belirlenmiştir. Böylece türetilen yüksekliklerden yararlanılarak Bouguer katmanının etkisi, Bouguer anomalilerine eklenerek grid merkezlerinde boşlukta gravite anomalileri elde edilmiştir (Abbak vd. 2012).

$\mathrm{Bu}$ işlemler her bir SYM kullanılarak ayrı ayrı gerçekleştirilmiştir. Yüksek doğruluklu ve çözünürlüklü Sayısal Yükseklik Modelinin bir etkisi de bu kısımda belli olacaktır. Cünkü gridleme işlemi sürecinde kullanılan SYM yükseklikleri gravite anomalisinin doğruluğunu doğrudan etkileyeceğinden yaklaşı jeoit ondülasyonunun da doğruluğuna etki yapacaktır.

Bunun yanı sira Stokes modifikasyonu çalışma sahasını çevreleyen yakın bölgede de gravite verilerine ihtiyaç duyar. Ancak uygulamalardaki zorluklar ve ekonomik nedenlerle çalışma sahasının dışındaki alanlarda yersel gravite verileri elde edilememektedir. Verilerin olduğu alanın $0.5^{\circ}$ lik dışındaki tampon bölgede yer alan veya enterpolasyonda hesaplanamayan gravite anomalileri EGM2008 (Earth Gravitational Model 2008) Modelinden türetilmiştir. EGM2008 Modeli, doğruluğu ve maksimum açınım derecesi yüksek olduğundan bu çalışmada tercih edilmiştir.

\subsection{Jeoit Modellerinin Değerlendirilmesi}

Yersel gravite anomalileri, GGM'den türetilen uzun dalga boylu bileşenler ve düzeltmeler KTH yaklaşımı ile LSMSSOFT (Abbak ve Üstün, 2015) programında değerlendirilerek her Sayısal Yükseklik Modeli için bölgesel gravimetrik jeoit oluşturulmuştur. Kesin ondülasyon değerine ulaşmak için yaklaşık ondülasyonlara getirilen düzeltmelerden topografik, atmosferik ve indirgeme düzeltmelerinin hesabındaki yükseklik değerleri SYM'lerden alınmıştır.

GPS-nivelman verileri yardımıyla hesaplanan bölgesel gravimetrik jeoit modellerinin dış doğruluk analizi gerçekleştirilmiştir. İki model (Gravimetrik ve Geometrik Model) arasındaki olası datum kayıklıkları ve trend nedenleriyle 7 parametreli benzerlik dönüşümü kullanılarak karşılaştırılmıştır (Tablo 2).

Tablo 2.Jeoit modellerin karşılaştırılması [cm]

\begin{tabular}{lcccl}
\hline Jeoit Modeli & Min. & Max. & Ort. & KOH \\
\hline Jeoit SRTM1 & -11.59 & 18.00 & 0.06 & 6.87 \\
Jeoit ASTER & -11.37 & 17.56 & 0.17 & 6.81 \\
\hline
\end{tabular}

Tablo 2 incelendiğinde her iki modelin de yakın sonuçlar verdiği görülmektedir. Her iki jeoit modelin en küçük ve en büyük değerler arasındaki fark aralığı hemen hemen aynıdır dolayısıyla bu sonucun modellerin karesel ortalama hatalarına da yansıdığı söylenebilir. Sonuç olarak SRTM1 Modelinin bölgesel jeoit modeline katkısının ASTER Modeli kadar olduğu anlaşılmaktadır.

ASTER ve SRTM1 Modeli kullanılarak oluşturulan gravimetrik jeoit modellerindeki farklar Şekil 3'de gösterilmektedir. Şekil 3'e göre iki jeoit modeli arasında anlamlı bir jeoit yükseklik farkı olmadığı görülmektedir. 


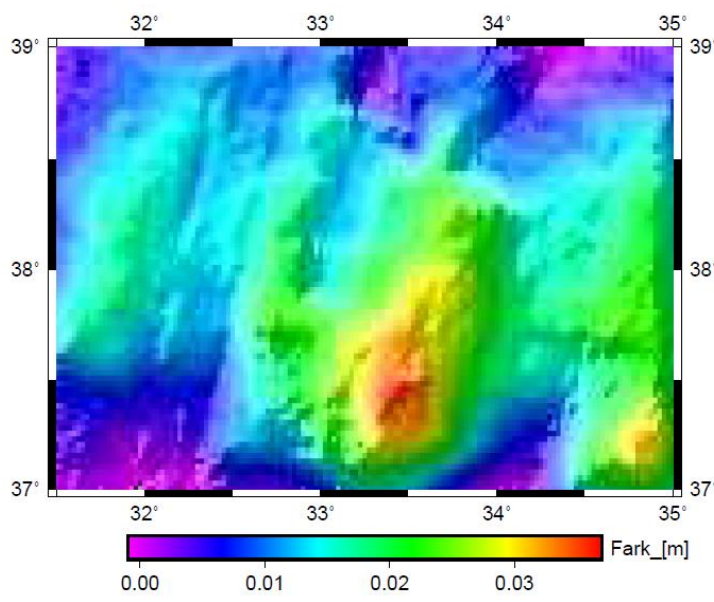

Şekil 3. Bölgesel gravimetrik jeoit modelleri arasındaki fark

\section{SONUÇLAR}

$\mathrm{Bu}$ çalışmanın temel amacı, yer bilimleri, doğal kaynakların yönetimi, mühendislik projeleri, askeri uygulamalar, üç boyutlu görselleştirme gibi birçok uygulama alanında kullanılmakta olan Global Sayısal Yükseklik Modellerinin doğruluğunun bölgesel gravimetrik jeoit modelinin doğruluğuna yaptığ1 katkıyı incelemektir. Her bir gravimetrik jeoit modelinin doğruluğu GPSnivelman verileriyle mutlak anlamda değerlendirilmiş̦tir. Bunun yanı sıra, SRTM1 ve ASTER Modelleri yine aynı sinırlar içerisinde karşıllaştırılmış ve yüksekliklerin birbirlerine göre değerlendirilmesi yapılmıştır.

Öncelikle, uygulama sahası içerisinde SRTM1 ve ASTER Global Sayısal Yükseklik Modellerinin dış doğruluk analizleri gerçekleştirilmiştir. İstatiksel sonuçlara göre; ASTER Modelinin karesel ortalama hatas1 $\pm 12.80 \mathrm{~m}, \quad$ SRTM1 Modelinin karesel ortalama hatas1 ise $\pm 11.64 \mathrm{~m}$ olarak hesaplanmıştır. $\mathrm{Bu}$ sonuçlara göre SRTM1 Modelinin ASTER Modeline göre 1.10 kat daha yüksek olduğu görülmektedir. Dış doğruluk analizinden SRTM1 ve ASTER Modelleri için elde edilen bölgesel doğrulukların, modellerin Global doğruluğundan daha yüksek olduğu belirlenmiştir.

Daha sonra, gravite değerleri doğrudan gravimetrik jeoit modellemede kullanılamadığından Stokes fonksiyonunda uygun şekilde boşlukta gravite anomalilerine indirgenmiştir. Bununla birlikte modelleme süreci gravite anomalilerinin eşit aralıklı olmasını zorunlu kıldığından enterpolasyon ile gridleme işlemi yapılması gerekmektedir. Ancak boşlukta gravite anomalileri topografya ile yüksek duyarlı olduğundan enterpolasyon sürecinde, daha yumuşak bir yüzeyi temsil eden Bouguer anomalilerine indirgenmiştir. $\mathrm{Bu}$ süreçte grid merkezindeki ortalama yükseklikler SYM ile belirlenerek tekrar boşlukta gravite anomalilerine dönüştürülmüştür. Modellemeye uygun hale getirilen yersel veriler ile GGM'den elde edilen uzak dalga boylu bileşenler Konya Kapalı Havzası ölçeğinde stokastik KTH yaklaşımıyla bir araya getirilip hesaplanarak bölgesel ölçekte iki farklı gravimetrik jeoit belirlenmiştir.

Bölgesel gravimetrik jeoit modelleri karşılaştırıldığında, ASTER Modeli ile elde edilen gravimetrik modelin doğruluğunun \pm $6.81 \mathrm{~cm}$, SRTM1 Modeli ile elde edilen gravimetrik modelin doğruluğunun ise \pm 6.87 $\mathrm{cm}$ olarak hesaplanmıştır. İstatiksel sonuçlara göre her iki jeoit modeli arasında anlamlı bir fark olmadığı, her iki SYM'ninde nerdeyse aynı sonuçlar verdiği görülmektedir. Modellerin benzer sonuçları vermesi, her iki modelin bölgesel doğruluklarının yakın, çözünürlüklerinin ise aynı olmasından kaynaklandığı değerlendirilmektedir. Ancak SRTM1 Modelinin olmadığ 1 yerlerde $\left(60^{\circ}\right.$ kuzey ve $50^{\circ}$ güney enlemleri dişında kalan alan) ASTER Modeli $\left(83^{\circ}\right.$ kuzey ve $83^{\circ}$ güney enlemleri arasında kalan alan) alternatif olarak kullanılabilir. Bunun yanı sıra söz konusu modellerin bölgesel jeoitlerin yüksek doğrulukla hesaplanmasında yeterli olduğunu göstermiştir.

\section{KAYNAKCA}

Abbak, R. A., 2014, Effect of ASTER DEM on the prediction of mean gravity anomalies: a case study over the Auvergne test region, Acta geodeatica et geofisica,49:491-502.

Abbak, R. A., 2017, Fiziksel Jeodezi: Teori ve Uygulama, Atlas Akademi, Konya.

Abbak, R. A., 2011, Global Yerpotansiyel Modellerinin Spektral Yöntemlerle Değerlendirilmesi ve Jeoit Belirleme İçin Yerel Olarak İyileştirilmesi, Doktora Tezi, Selçuk Üniversitesi, Konya. 
Abbak, R. A. and Ustun, A. 2015, A software package for computing a regional gravimetric geoid Model bythe KTH method. Earth Science Informatics, $8(1): 255-265$.

Abbak, R. A., Üstün, A., Ellmann, A., 2012, Ortalama gravite anomalilerinin enterpolasyon basit ve tamamlanmış bouguer yaklaşımının karşılaştırılması, jeodezi ve jeoinformasyon dergisi, Cilt: 1 , Say1: 1, 45-52.

Akyilmaz, O., Ustun, A., Aydin, C.; Arslan, N., Doganalp, S., Guney, C., Mercan, H., Uygur, S.O., Uz, M., Yagci, O. 2016, ITU_GGC16 The combined Global gravity field Model including GRACE \& GOCE data up to degree and order 280. GFZ Data Services. http://doi.org/10.5880/icgem.2016.005 Erişim tarihi: 28.02.2018

ASTER (2018) The Advanced Spaceborne Thermal Emissionand Reflection Radiometer. http://gdem.ersdac. jspacesystems.or.jp Erişim tarihi: 28.02.2018.

Bildirici, İ. Ö., Abbak, R.A. (2017) Comparison of ASTER and SRTM digital elevation models at one-arc-second resolution over Turkey, Selcuk University Journal of Engineering Science and Technology, 5/1,16-25.

Bjerhammar, A. (1973) Theory of errors and generalized matrix inverses. Elsevier, Amsterdam.

Demir, S., Abbak R. A., 2017, Regional Analysis of Recent Global Geopotential Models: A Case Study In Turkey, $17^{\text {th }}$ International Multidisciplinary Scientific Geoconference SGEM, Bulgaria.

Ellmann, A. ve Sjöberg, LE. 2004, Ellipsoidal correction for the modified Stokes' formula. Boll Geod Sci Aff 63:3.

ICGEM, 2018, International Centre for Global Earth Models, Erişim tarihi: 28.02.2018.

ITU_GGC16,2018,http://www.geo.itu.edu.tr/gravit y/ITU_GGC16.html. Erişim Tarihi: 28.02.2018

Kiamehr, R. ve Sjöberg L. E. 2005, Effect of the SRTM Global DEM on the determination of a high-resolutiongeoid Model: a case study in Iran, Journal of Geodesy, 79: 540-551.

Merry, CL. 1999, DEM-inducederrors in developing a quasi-geoid Model for Africa. Journal of Geodesy, 77, pp: 537542.

Sideris, M. G. 1994, Geoid determination by FFT Techniques, International School for the determination and use of Geoid, Milan, İtalya.

Sjöberg, LE. 1999, The IAG approach to the atmospheric geoid correction in Stokes' formula and a new strategy. Journal of Geodesy 73:362-366.

Sjöberg, LE. 2003, A solution to the downward continuation effect on the geoid determination by Stokes' Formula. Journal of Geodesy, 77:94-100.

Sjöberg, LE. 2007, The topographic bias by analytical continuation in physical geodesy. Journal of Geodesy, 87:345-350.

SRTM (2018) Shuttle Radar Topography Mission. http://www2.jpl.nasa.gov/srtm Erişim tarihi: 28.02.2018. 